\title{
Miniaturized Platinum temperature sensors with high resistance for Smart Systems
}

\author{
Dr. Kiesewetter, Olaf \\ UST Umweltsensortechnik GmbH \\ Dieselstr. 2, 98716 Geschwenda
}

The development and realization of smart system for applications in aerospace industry, automotive industry, security engineering, logistics, medical engineering a.o. put new and extended requirements to sensors and sensor systems. The optimized adaptation of the sensor system to the measurement objective, especially with regard to miniaturization and integration in overall system concepts, reduction of power consumption, improvement of measurement accuracy, reduction of response times, extension of the temperature range, long term stability and reliability are only a few of the requirements to temperature sensors.

UST Umweltsensortechnik GmbH as a leading manufacturer of innovative ceramic sensor technology for temperature and gas measurements masters these challenges successfully by the visionary as well as market-driven and application-oriented development and production of Platinum-Thinfilm-temperature sensor elements and custom designed semi-finished temperature probes.

The structural design of a ceramic Pt-Thinfilm-Temperature sensor element is shown in figure 1.

Simplified a sensor element consists of a ceramic carrier with a structured platinum layer, covered with a passivating layer and the connecting leads.

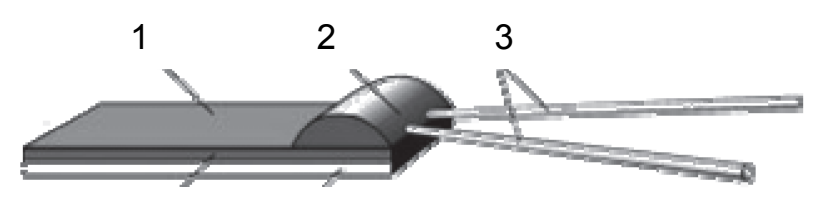

4

5
1... passivating layer

2... locking layer

3... connection leads

4... structured platinum layer

5... $\mathrm{Al}_{2} \mathrm{O}_{3}$-carrier substrate

Figure 1: Structural design of a ceramic Thinfilm-Temperature sensor element

Currently, the manufacturing of platinum structures of micro-structured Pt-Thinfilm-Temperature sensors is done with solid-state lasers. By using this technology $10 \mu \mathrm{m}$ structures can be created. This results in a minimum chip size of $5 \mathrm{~mm}^{2}$ for a Pt1000 temperature sensor - the chip size of a Pt10000 temperature sensor would be about $35 \mathrm{~mm}^{2}$. Consequently, the manufacturing of highest resistance temperature sensors with industry-strength chip dimensions applying this technology will not be possible.

On initiative of UST Umweltsensortechnik GmbH in collaboration with Fraunhofer IPM in Freiburg an innovative Lift-off Technolog for the structuring of platinum on ceramics substrates was developed. This photolithographic procedure enables the creation of minimum web thicknesses and electrode distances for platinum temperature sensors with chip sizes less then $1 \mathrm{~mm}^{2}$.

Between 2006 and 2008, a clean-room was set-up and the photolithographic procedure was implemented at the facilities of UST Umweltsensortechnik $\mathrm{GmbH}$. This investment was supported by the Free State of Thuringia ${ }^{1)}$. The clean room meets the requirements of the clean-room class ISO2 according to ISO14644-1 (class 100 according to obosolete US fed. Std. 209E) and provides the environment for the manufacturing of smallest micro-structures.

These technical and technological prerequisits have been and continue to be fundamental to the successful realization of further product innovations. One of these innovations is the miniaturization of high-resolution temperature sensors for the application in RFID systems. Within the scope of the project TRACK ${ }^{2)}$ supported by the Federal Ministry of Education and Research UST Umweltsensortechnik $\mathrm{GmbH}$ has developed a micro-structured SMD temperature sensor (according to DIN EN 60751) with chip size of about $4 \mathrm{~mm}^{2}$ only (figure 2 ). 


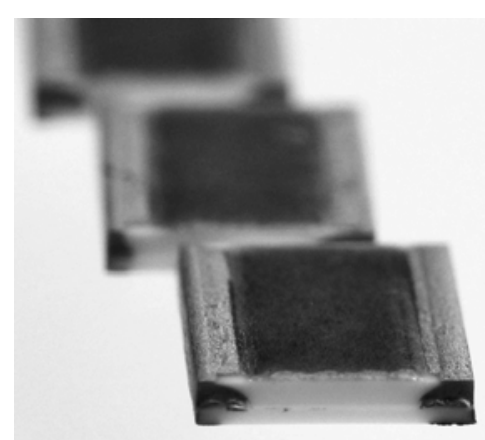

\section{$1 \mathrm{~mm}$}

Figure: 2: SMD Pt10000 (chip area appr. $4 \mathrm{~mm}^{2}$ )

The major techological challenge was basically the structuring of smallest platinum tracks (about $3 \mu \mathrm{m}$ ) on a, compared to slilicon-wafer, very rough ceramics surface (figure 3). As any dust partice existing in the micro-structuring process will result in one or more defect chips, the creation of structures of this kind is only possible in a clean room, nearly free of any particle. The micro-structuring of the platinum is carried out by clean-room processes like Photolithography, Wet-Chemical Etching and Lift-Off-Procedures that are typically used in the silicon technology, only.

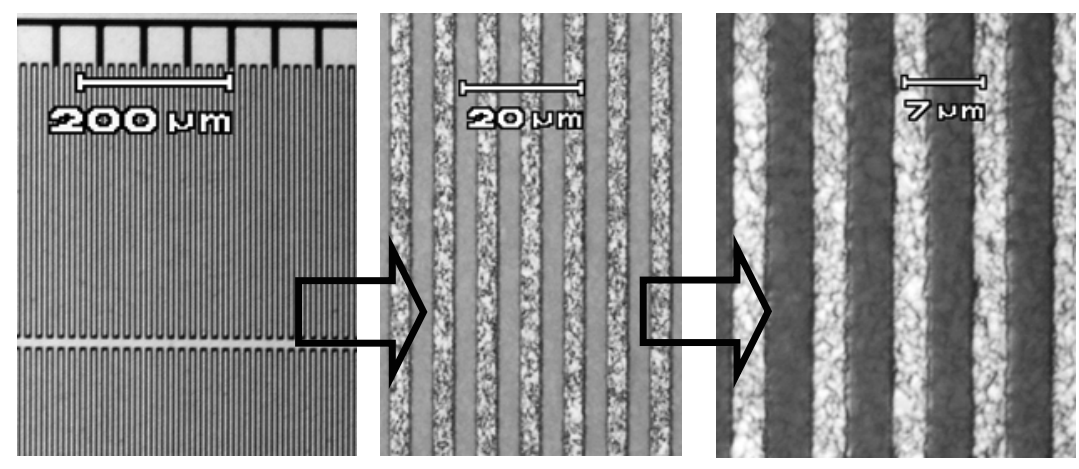

Figure 3: Pt-Structure of a Pt10000 on a ceramic substrat with a "rough surface"

During the project these thechnologies could be successfuly transferred to ceramics-wafers, the standard-substrates used by UST by default. The application of this technology enables a more efficient manufacturing of temperature sensor elements by e.g. the reduction of productions steps and higher production yields.

The advantages of highest-resistance temperature sensors compared to current standard temperaturesensors are the following:

The temperature-sensitive change of resistance of a Pt10.000, for instance, is higher by factor 100 compared to a Pt100. An evaluation electronics can resolve the change of resistance more detailed, resulting in a more precize measurement result.

Furthermore, due to a higher voltage stroke a lower measurement current is necessary. Thus, highestresistance temperature sensors have a lower power consumption - the electrical power of a measurment with a Pt100 is about $900 \mu \mathrm{W}$, with a Pt10000 merely about $25 \mu \mathrm{W}$. Accordingly, the energy demand is many times lower. This issue becomes more and more important, especially, in self-sustaining systems with a limited energy storage, but long-term measurment periods.

The contact resistance of the connectors is another important issue on the set-up of measurement systems, even on the integration of sensors. At an Pt10000 this resistance is low in relation to the actual sensor resistance and doesn't have to be regarded. Consequently, the sensor can be connected to the measurement system by a 2-wire cable. Expansive 3- or 4-wire circuts, used for compensation of the 
wire-resistance are no longer nessecary. This results in a reduction of components and costs in measurment systems.

The photolithographic technology enables the manufacturing of new generation highest-resistance temperature sensors by UST Umweltsensortechnik GmbH. Additionally, even the currrently offered temperature sensors can be produced in smaller chip dimensions (e.g. Pt1000 on $1 \mathrm{~mm}^{2}$ ). They will be provided with the Standard-Temperature-Coefficient TC $3850 \mathrm{ppm} / \mathrm{K}$ as well as TC $3750 \mathrm{ppm} / \mathrm{K}$.

UST Umweltsensortechnik GmbH was established in 1991 supported by Federal Ministry of Education and Research (TOU-program). Today, UST Umweltsensortechnik GmbH is a medium sized company, successfully acting in the global market.

The product range includes:

Platinum temperature sensor elements based on a ceramic chip with a thin film laser structured platinum layer (temperature range from -200 to $+1000^{\circ} \mathrm{C}$ ) in various $\mathrm{R}_{0}$-values (Pt $10 \ldots \mathrm{Pt} 10000$ ), shapes, dimensions and elements with custom-designed leads;

Custom designed semi finished temperature probes from $-100^{\circ} \mathrm{C}$ to $+1000^{\circ} \mathrm{C}$ (screw-in temperature probes, plug-in temperature probes, immersion temperature probes);

MOS gas sensor elements for a wide range of applications, i.e. environmental technology, automotive applications, leak detection, location of smouldering underground fires, detection of lower explosive limit (LEL), air quality monitoring and process measurement. Various sensor types for the detection of $\mathrm{CO}, \mathrm{H}_{2}, \mathrm{C}_{2} \mathrm{H}_{5} \mathrm{OH}, \mathrm{CH}_{4}, \mathrm{NO}_{2}, \mathrm{O}_{3}, \mathrm{NH}_{3}$, hydrocarbons $\left(\mathrm{C}_{\mathrm{x}} \mathrm{H}_{\mathrm{x}} \ldots\right.$ from $\mathrm{C}_{1}$ to $\left.\mathrm{C}_{8}\right)$, $\mathrm{R} 134 \mathrm{a}$ a. o. are available. Also gas sensor arrays with a measuring range depending on the gas from some $\mathrm{ppb}$ to the Vol\%-Range and a patented TRIPLE-sensor-module with artificial intelligence are offered.

Portable gas detectors for the quick and selective detection/determination of different gas types (Hydrogen, $\mathrm{CO}_{2}$, Methane, Refrigerants a. o.);

Stationary detectors for combustible gases and selected $\mathrm{VOC}$ markers in the range of a few ppm up to the LEL in VOL\%.

Main application fields of the products are automotive engineering, industrial process measurement, energy technology, environmental technology, safety engineering and medical engineering.

UST Umweltsensortechnik GmbH is certified according to ISO/TS 16949:2002, DIN EN ISO 14001:2005, ATEX RL 94/9/EG Annex IV DIN EN 13980:2003.

${ }^{1)}$ Project: Einführung der Photolithographietechnologie (Project reference: 2005 TE 0220)

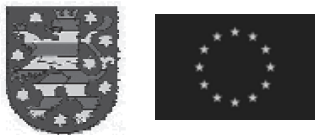

The project was supported by the Free State of Thuringia and was co-financed by the European Union in the Frame of European regional development fund (ERDF).

${ }^{2)}$ Cooperative research project: TRACK (Project reference: 16SV2037)

SPONSORED BY THE

Federal Ministry

of Education

and Research 